\title{
PENGARUH DUKUNGAN KELUARGA TERHADAP KEMAMPUAN MELAKUKAN AKTIVITAS SEHARI-HARI PADA PENDERITA PASCA STROKE NON HEMORAGIC DI RUMAH SAKIT PELAMONIA MAKASSAR
}

\section{THE EFFECT OF FAMILY SUPPORT ON THE ABILITY TO PERFORM DAILY ACTIVITIES IN POST STROKE PATIENTS NON HEMORAGIC IN PELAMONIA HOSPITALMAKASSAR}

\begin{abstract}
Suwardi ${ }^{1}$
Univesitas Indonesia Timur Makassar, Indonesia $^{1}$ email: suwardiskep001@gmail .com

IJI Publication p-ISSN: 2774-1907 e-ISSN: 2774-1915 Vol. 2, No. 1, pp. 31-35 Nopember 2021

Unit Publikasi Ilmiah
Intelektual Madani
Indonesia

\section{PENDAHULUAN}

Berdasarkan data World Health Organization (WHO) pada tahun 2017 Stroke merupakan penyebab umum kematian urutan ketiga dinegara maju setelah penyakit kardiovaskular dan kanker. Setiap tahun, lebih dari 700.000 orang Amerika mengalami stroke, dan 150.000 orang meninggal akibat stroke atau akibat komplikasi segera setelah stroke. Setiap saat 4,7 juta orang di Amerika Serikat pernah mengalami stroke, mengakibatkan pelayanan kesehatan yang berhubungan dengan stroke mengeluarkan biaya lebih 18 milyar setiap Tahun (Goldszmidt, 2017).

Abstrak: Tujuan penelitian untuk untuk mengetahui Pengaruh Dukungan Keluarga Terhadap Kemampuan Melakukan Aktivitas Sehari-hari Pada Penderita Pasca Stroke Non Hemoragic. Penelitian ini dilakukan di Rumah Sakit Pelamonia Makassar itian ini menggunakan metode penelitian Deskriptif Analitik dengan desain cross Sampel dalam penelitian ini berjumlah 40 orang yang keseluruhannya adalah semua penderita Pasca Stroke Non Hemoragic yang ada di Rumah Sakit Pelamonia Pengambilan data melalui kuesioner. Analisis data dilakukan secara analisis univariat ariat dengan menggunakan uji chi square. Hasil penelitian dapat disimpulkan bahwa ada pengaruh kemampuan aktifitas sehari-hari dengan pasca stroke non hemoragic $(p=0,000)$, ada pengaruh dukungan keluarga dengan pasca stroke non emoragic $(p=0,000)$. Hasil analisis bivariat, Chis-Quer $p$ (asymp.Sig) $=<0,05$, yang untuk kemandirian orang pasca stroke.

Pascastroke.

Abstract: The aim of the study was to determine the effect of family support on the ability to carry out daily activities in non-hemorrhagic post-stroke patients. This research was conducted at the Pelamonia Hospital Makassar. This research used descriptive analytical research method with cross sectional design. The sampling technique in this study was accidental sampling. The sample in this study amounted to 40 people, all of whom were non-hemorrhagic post-stroke patients at the Pelamonia Hospital. Collecting data through questionnaires. Data analysis was carried out by ariate and bivariate analysis using the chi square test. The results of the study concluded that tivariate analysis, Chis-Quer $p$ (asymp. Sig) $=<0.05$, which means significant. So Ho is well as create activities that are beneficial for the independence of post-stroke people.

Keywords: Activity of Daily Living (ADL), Family Support, Independence, Poststroke.
\end{abstract}


Penderita stroke yang memiliki riwayat stroke nonhemoragic memiliki peluang yang lebih besar untuk mengalami stroke ulangan dibanding penderita stroke dengan riwayat stroke hemoragic sebelumnya (Anjani, 2015). Persentase serangan stroke berulang dalam waktu 30 hari adalah 3\%-10\%, dalam waktu 1 tahun 5\% $-14 \%$, dan dalam waktu 5 tahun $25 \%$ - 40\%. Beberapa studi lain menyebutkan bahwa kejadian stroke berulang $29,52 \%$, yang paling sering terjadi pada usia 60-69 tahun (36,5\%), dan pada kurun waktu 1-5 tahun (78,37\%) (Handayani, 2016) dan Fathimah (2016).

Pada hasil penelitian yang dilakukan oleh Irdawati (2016) menyatakan terdapat hubungan antara pengetahuan keluarga terhadap tingkat kesehatan penderita stroke. Saat ini telah banyak dikembangkan beberepa instrumen yang berguna untuk menilai outcome dan ADL salah satunya Katz index. Penilaian yang tepat dan akurat dari disabilitas dan ADL pada pasien stroke sangat penting untuk kualitas perawatan dan pengukuran outcome dari penanganan stroke serta dapat digunakan untuk menentukantingkat disabilitas dan prognosis pasien (Kwon, 2017). Selain menyebabkan kematian, stroke juga bertanggung jawab atas terjadinya disabilitas jangka panjang. Motivasi yang rendah dan harapan untuk sembuh pada diri penderita serta kurangnya dukungan keluarga sangat berpotensi menimbulkan beban dan berujung pada stres. Peran keluarga dalam membantu pasien stroke adalah memberikan perawatan pada anggota keluarga yang sakit atau tidak dapat membantu dirinya sendiri karena cacat atau usianya yang terlalu muda. Maka perawatan yang diberikan keluarga kepada pasien pasca stroke sangat penting untuk mencegah timbulnya stroke berulang, seperti pengaturan diit, memotivasi dan mengawasi penderita melakukan latihanlatihan atau aktivitas sesuai kemampuannya serta membantu kebutuhan sehari-hari
(Junaidi, 2017).

Dukungan secara optimal yang dilakukan oleh keluarga kepada pasien dapat menimbulkan semangat pada diri pasien sehingga dapat tercapai peningkatan status kesehatan yang lebih baik dan jika dukungannya berkurang atau bahkan tidak ada, maka tingkat keberhasilan penyembuhan dan pemulihan (rehabilitasi) akan sangat berkurang (Festy, 2017). Rehabilitasi medik pada penderita bertujuan untuk memulihkan fungsi saraf yang rusak akibat stroke dan mencegah terjadinya komplikasi kecacatan lebih lanjut serta dapat membuat pasien mandiri dalam melakukan aktifitas tanpa harus tergantung pada orang lain (Harsono, 2016).

Stroke adalah suatu penyakit defisit neurologis akut yang disebabkan oleh gangguan pembuluh darah otak, terjadi secara mendadak dan menimbulkan gejala atau tanda yang sesuai dengan daerah otak yang terganggu (Bustan, 2017). Klasifikasi stroke dibagi menjadi dua, yaitu pendarahan yang mendadak karena pecahnya pembuluh darah di otak (stroke hemoragic), dan asupan darah ke otak berkurang atau pengumpulan darah atau penyumbatan pembuluh darah (Nonhemoragic) (Sutrisno, 2017). Stroke non hemoragik adalah suatu penyakit yang diawali dengan terjadinya serangkaian perubahan dalam otak yang terserang yang apabila tidak ditangani dengan segera berakhir dengan kematian bagian otak tersebut (Junaidi, 2017). Stroke Non Hemoragik memiliki persentase paling besaryaitu sebesar $80 \%$, terbagi atas subtipe stroke trombotik dan embolik yang dapat mengurangi sirkulasiatau kebutuhan darah di otak atau mengakibatkan kematian neuron yang diperlukan otak (Agoes, 2017). Pasien pasca stroke mengakibatkan berbagai masalah kecatatan fisik seperti mengalami kelemahan atau kelumpuhan separuh badan (90\%), kesulitan berjalan atau gangguan keseimbangan $(16,43 \%)$, mandi $(14,04 \%)$, 
makan (3,39\%), gangguan inkontinensia urin (15-20\%). Suwantara (2004) menyatakan, kira-kira30\% penderita stroke menunjukkan gangguan bicara, sekitar 15$25 \%$ mengalami gangguan memori yang mengakibatkan terganggunya aktivitas sehari-hari pada pasien tersebut. Kelemahan atau kelumpuhan ini seringkali masih dialami pasien sewaktu keluar dari rumah sakit.

\section{METODE}

Jenis penelitian ini adalah dengan menggunakan jenis penelitian kuantitatif dengan pendekatan "cross sectional study". Penelitian ini dilakukan di Rumah Sakit Pelamonia Makassar. Populasi pada penelitian ini adalah semua Penderita Pasca Stroke Non Hemoragic yang ada di Rumah Sakit Pelamonia Makassar dan sekaligus menjadi sampel. Teknik pengumpulan data dari responden dengan cara wawancara dan menggunakan lembar kuisioner sebagai alat bantu untuk mengetahui variabel independen (Kemampuan ADL \& Dukungan Keluarga) dan variabel dependen (Pasca Stroke Non Hemoragic). Hasil penelitian dilakukan dalam bentuk analisis Univariat dan Analisis Bivariat.

\section{HASIL DAN DISKUSI}

\section{Deskripsi Hasil Penelitian}

\section{Analisa Univariat}

\section{Data Demografi}

Setelah dilakukan pengumpulan data maka didapatkan data karakteristik responden berdasarkan jenis kelamin, kelompok umur dan tingkat pendidikan yang dapat dilihat pada tabel sebagai berikut :

Tabel 1

Distribusi Frekuensi Responden

Berdasarkan Jenis Kelamin

\begin{tabular}{ccc}
\hline Jenis Kelamin & $\mathrm{n}$ & $\%$ \\
\hline Laki-Laki & 15 & 37,5 \\
Perempuan & 25 & 62,5 \\
\hline Total & 40 & 100,0
\end{tabular}

Sumber data : Data Prime
Berdasarkan tabel 1, dapat diketahui bahwa dari 40 responden berjenis kelamin laki-laki sebanyak 15 orang $(37,5 \%)$ dan berjenis kelamin perempuan 25 orang $(62,5 \%)$.

Tabel 2

Distribusi Frekuensi Responden Berdasarkan Umur

\begin{tabular}{ccc}
\hline Umur & $\mathrm{n}$ & $\%$ \\
\hline $30-49$ & 20 & 50,0 \\
$>50$ & 20 & 50,0 \\
\hline Total & 40 & 100,0 \\
\hline
\end{tabular}

Sumber data : Data Primer

Berdasarkan tabel 2, dapat diketahui bahwa dari 40 responden yang berumur antara umur antara 30-49 tahun sebanyak 20 orang dengan nilai persentase $(50,0 \%)$ dan berumur $>50$ tahun berjumlah 20 orang dengan persentase $(50,0 \%) \%)$.

Tabel 3

Distribusi Frekuensi Responden Berdasarkan Pendidikan

\begin{tabular}{ccc}
\hline Pendidikan & $\mathrm{n}$ & $\%$ \\
\hline SD & 11 & 27,5 \\
SMP & 9 & 22,5 \\
SMA & 15 & 37,5 \\
PT & 5 & 12,5 \\
\hline Total & 40 & 100,0
\end{tabular}

Sumber data : Data Primer

Berdasarkan tabel 3, dapat diketahui bahwa dari 40 responden yang berpendidkan SD berjumlah 11 orang dengan presentase (27,5\%), berpendidikan SMP berjumlah 9 orang dengan presentase $(22,5)$ berpendidkan SMA sebnayak 15 orang dengan presentase $(37,5)$ dan berpendidikan PT sebanyak 5 orang dengan presentase $(12,5 \%)$.

2. Kemampuan Aktifitas Sehari-Hari

Tabel 4

Distribusi Frekuensi Resonden Berdasarkan Kemampuan Aktifitas Sehari-Hari Pada Penderita Pasca Stroke Non Hemoragic di Rumah Sakit Pelamonia Makassar 2018

Aktivitas sehari-hari $\quad \mathrm{n} \quad \%$

\begin{tabular}{ccc}
\hline Mandiri & 11 & 27,5 \\
Tergantung & 29 & 72,5 \\
\hline Total & 40 & 100,0
\end{tabular}

Sumber data : Data Primer

Berdasarkan tabel 4, responden yang memiliki aktifitas sehari-hari yang tergantung 
sebanyak 29 orang (75,5\%) sedangkan responden yang memiliki aktivitas sehari-hari yang mandiri adalah sebanyak 11 orang $(27,5 \%)$.

\section{Dukungan Keluarga}

Tabel 5

Distribusi Frekuensi Resonden Berdasarkan ukungan Keluarga Pada Penderita Pasca Stroke Non Hemoragic di Rumah Sakit Pelamonia Makassar 2018

\begin{tabular}{|c|c|c|}
\hline Dukungan Keularga & $\mathrm{n}$ & $\%$ \\
\hline Baik & 10 & 25,0 \\
\hline Tidak Baik & 30 & 75,0 \\
\hline Total & 40 & 100,0 \\
\hline
\end{tabular}

Sumber data : Data Primer

Berdasarkan tabel 5 Responden yang mendapat dukungan keluarga tidak baik lebih banyak yaitu sebesar 30 orang $(75,0 \%)$ dibandingkan responden yang dukungan keluarga baik yaitu sebesar 10 orang $(25,0 \%)$.

\section{Analisa Bivariat}

1. Pengaruh Kemampuan Aktifitas seharihari dengan Pasca Stroke Non Hemoragic

Hasil analisis dengan menggunakan uji chi-square diperoleh nilai $\mathrm{P}=0,000(<0,05)$ sehingga $\mathrm{Ha}$ diterima. Hal ini menunjukkan bahwa ada pengaruh dukungan keluarga terhadap kemampuan aktifitas sehari-hari dengan pasca stroke non hemoragic di rumah sakit pelamonia.

2. Pengaruh Dukungan Keluarga dengan Pasca Stroke Non Hemoragic

Hasil analisis dengan menggunakan uji chi-square diperoleh nilai $\mathrm{P}=0,000(<0,05)$ sehingga $\mathrm{Ha}$ diterima. Hal ini menunjukkan bahwa ada pengaruh dukungan keluarga terhadap kemampuan aktivitas sehari-hari dengan pasca stroke non hemoragic di rumah sakitpelamonia.

\section{Pembahasan}

Keadaan pasca stroke dalam perjalanannya sangat beragam, bisa pulih sempurna atau bisa sembuh dengan cacat ringan, sedang, dan cacat berat dan memang stroke merupakan penyakit yang paling banyak menyebabkan cacat. Oleh sebab itu, pasien disarankan untuk mempersiapkan diri dan bila perlu mengadakan penyesuaian dalam segala hal, terutama dalam perjalanan sebagai pegangan saat masa pemulihan dan meningkatkan kemandirian aktifitasnya Kemandirian berarti tanpa pengawasan, pengarahan, atau bahkan bantuan pribadi aktif, kecuali secara spesifik diperlihatkan. Didasarkan pada status aktual, bukan pada kemampuan, individu yang menolak melakukan suatu fungsi dianggap tidak melakukan fungsi, meskipun dianggap mampu. (Thamher, 2016). Penentuan kemandirian fungsional dilakukan untuk mengindentifikasi kemampuan dan keterbatasan klien serta menciptakan pemilihan intervensi yang tepat. Disamping berhubungan dengan diagnosis medis, status fungsional berhubungan dengan perawatan kebutuhan klien, resiko instusionalisasi, dan mortalitas (Kushariyadi 2017). Penelitian Surono \& Saputro (2013) menyimpulkan ada hubungan antara dukungan keluarga dengan motivasi untuk melakukan ROM pada pasien pasca stroke. Pengaruh hubungan dukungan keluarga secara jelas cenderung lebih efektif, jika langsung dilakukan anggota keluarganya, seperti anak-cucu. Sebab bagaimana pun, bobot kualitas komunikasi dan interaksi semacam itu susah digantikan 100\% oleh pihak lain. Apalagi jika keluarga berkeinginan yang kuat untuk merehabilitasi fungsi bicara dan senso-motoriknya (Beladona 2015). Dukungan keluarga sangat penting untuk menjaga dan memaksimalkan penyembuhan dan pemulihan fisik dan kognitif pasien. Keluarga merupakan satusatunya tempat yang sangat penting untuk memberikan dukungan, pelayanan serta kenyamanan bagi pasien menurut Depkes RI: 2003 di kutip dalam Setiadi (2018). Dukungan keluarga menjadikan keluarga mampu berfungsi dengan berbagai kepandaian dan akal sehingga akan meningkatkan kesehatan dan adaptasi keluarga dalam kehidupan (Setiadi 2008).

Asumsi peneliti bahwa mengatakan 
bahwa penderita stroke tidak dapat disembuhkan secara total, namun apabila ditangani dengan baik maka dapat meringankan beban penderita, meminimalkan kecacatan dan mengurangi ketergantungan pada orang lain dalam beraktivitas. Pasien stroke membutuhkan penanganan yang komprehensif termasuk upaya pemulihan dan rehabilitasi dalam jangka lama bahkan sepanjang sisa hidup pasien.

\section{KESIMPULAN}

Ada pengaruh dukungan keluarga terhadap kemapuan aktifitas sehari-hari dengan pasien pasca stroke non hemoragic diperoleh bahwa kemampuan aktifitas seharihari dengan katagori tergantung sebanyak 24 responden $(60,0 \%)$ yang memiliki kemampuan aktifitas sehari-hari katagori mandiri tinggi sebanyak 1 responden $(2,5 \%)$. Hasil analisis dengan menggunakan uji chisquare diperoleh nilai $\mathrm{P}=0,000 \quad(<0,05)$ sehingga $\mathrm{Ha}$ diterima. Hal ini menunjukkan bahwa ada pengaruh dukungan keluarga terhadap kemampuan aktifitas sehari-hari dengan pasca stroke non hemoragic di Rumah Sakit Pelamonia) dan merupakan faktor yang dominan dari faktor yang diteliti. Ada Pengaruh Dukungan Keluarga terhadap kemampuan melakukan aktivitas sehari-hari dengan Pasca Stroke Non Hemoragic di rumah sakit Pelamonia diperoleh bahwa ada sebanyak 23 responden (57,5\%) yang memiliki dukungan Keluarga pasien dan kurang, sedangkan yang memiliki dukungan Keluarga baik sebanyak 2 responden (5,0\%). Hasil analisis dengan menggunakan uji chisquare diperoleh nilai $\mathrm{P}=0,000 \quad(<0,05)$ sehingga Ha diterima. Hal ini menunjukkan bahwa ada pengaruh dukungan Keluarga dengan pasca stroke non hemoragic di Rumah Sakit Pelamonia.

\section{REFERENSI}

Abidin. (2017). Life After Stroke: Reconstructing Everyday Life. University of Kent: Centre for Helath Service Studies.

Bustan. (2017). Psikologi Sosial. Jakarta: Penerbit Erlangga.

Depkes RI. (2017). Gizi dan Kesehatan Masyarakat. Jakarta: PT. Raja Grafindo Persada.

Festy. (2017). Stroke, Panduan Bergambar Tentang Pencegahan dan Pemulihan Stroke Edisi 2. Jakarta: PT Bhuana Ilmu Populer.

Goldmidti. (2014). Buku Saku Gerontologi. Jakarta: EGC.

Harsono. 2014. Psychology of Adjusment. Illinois: The Dorsey Press.

Junaidi, I. (2018). Panduan Praktis Pencegahan dan Pengobatan Stroke. Jakarta: PT. Bhuana Ilmu Populers.

Kwon. (2014). Genetics of Ischemic Stroke: Indian Perspective. Neurology India, 60(5), 498-503. 